сотагексал, лизиноприл, амлодипин ) достигнута 1 степень АГ, уредилась желудочковая экстрасистолия .

C диагнозом дисгормональная кардиомиопатия. Желудочковая экстрасистолия высоких градаций. Вторичная артериальная гипертония. Степень 1 ( исход 3 степени). Миома матки гигантских размеров . Вторичный эритроцитоз пациентка была переведена в гинекологическое отделение, где произведена надвлагалищная ампутация матки с придатками . Операция, наркоз и послеоперационный период прошли без осложнений. Гистологически определена лей-фибромиома .

В послеоперационном периоде больная наблюдалась совместно кардиологом и гинекологом . Достигнута и сохранялась нормотензия, купирована желудочковая экстрасистолия ( что подтверждено проведенным суточным мониторированием АД и ЭКГ), нормализовались показатели красной крови ( гемоглобин - 145 г/л, Эр - 4.05 х 10х12/L ). Пациентка выписана под наблюдение кардиолога, гематолога и гинеколога по месту жительства в удовлетворительном состоянии .

Вывод:

Таким образом, проведение оперативного лечения больным с гигантской миомой матки приводит к улучшению показателей суточного монигорирования АД и ЭКГ

\section{СПИСОК ЛИТЕРАТУРЫ :}

1. Руководство по эндокринной гинекологии под редакцией Е.М. Вихляевой . ООО «Медицинское информационное агентство», 2006 г

2. Татарчук Т.Ф. Сокольский Я.П. Эндокринная гинекология ( клинические очерки).

3. Вестник аритмологии № 31 от 15.04.2003 г стр. 60-71 «идиопатические желудочковые нарушения ритма» ( анализ проблемы) . Пармон Е.В. Трешкур Т.В. Шляхто Е.В.

4. «Вторичные

кардиомиопатии дисгормонального генеза : особенности патогенеза, диагностики, клиники, лечения» Мкртчян В.Ф. Москва 2008 г . Автореферат.

\title{
О НЕЙРОПСИХОЛОГИЧЕСКОЙ РЕАБИЛИТАЦИИ ПРИ ЭПИЛЕПСИИ
}

Токарева Наталья Геннадьевна Канд. мед. наук, доцент кафедры нервных болезней и психиатрии ФГБОУ ВО «МГУ им. Н.П. Огарева», Медицинский институт, г.Саранск Железнова Елена Валерьевна Д-р мед.наук, ведущиий научный сотрудник клиники экзогенно-органических расстройств и эпилепсии, г.Москва Московский НИИ психиатрии филиал «ФМИЦ ПН им. В.П. Сербского» Минздрава России DOI: $\underline{10.31618 / \mathrm{ESU} .2413-9335.2019 .2 .64 .224}$

\section{АННОтАЦИЯ}

Проведен анализ реабилитационных мероприятий при эпилепсии. Изучены факторы, участвующие в формировании нейропсихологической реабилитации. Рассмотрены взаимодействие и взаимовлияние нейропсихологической реабилитации и восстановление высших психических функций. Данные характеристики представляют интерес для врачей, клинических психологов и других специалистов, участвующих в проведении лечебно-реабилитационных мероприятий больным эпилепсией.

\section{ABSTRACT}

The analysis of rehabilitation measures for epilepsy was carried out. The factors involved in the formation of neuropsychological rehabilitation were studied. The interaction and interaction of neuropsychological rehabilitation and restoration of higher mental functions are considered. These characteristics are of interest to physicians, clinical psychologists and other specialists involved in conducting therapeutic and rehabilitation measures for patients with epilepsy.

Ключевые слова: нейропсихологическая реабилитация, личность, эпилепсия.

Keywords: neuropsychological rehabilitation, personality, epilepsy.

Реабилитация - это особая технология, состоящая из техник и форм организации воздействия, направленных на восстановление личного и социального статуса пациента. Методы реабилитации подбираются строго индивидуально и зависят от ряда факторов: болезни человека, тяжести этой болезни, с одной стороны, и характера больного, его окружения, его мотивы, цели - с другой. Необходимо использовать такие технологии и техники, содержание которых опосредовано личностью пациента. Реабилитация может дать результат только при комплексном интегративном воздействии, в первую очередь, на человека с тем или иным дефектом в целом, а затем только на сам дефект. Комплексное взаимодействие включает медицинские, психологические и социальные аспекты реабилитации, целью которой является преодоление заболевания и восстановление личностного и социального статуса пациента, а 
также возвращение пациента в нормальную социальную среду $[1,3,4]$.

Эпилепсия - распространенное нервнопсихическое заболевание, которое сопровождается наличием психологических и социальных проблем $[2,5,6]$. Больные эпилепсией страдают неврологическими и психическими признаками заболевания [7,8,9]. Нейропсихологическая реабилитация играет важную роль при этом заболевании. Рассмотрим основные составляющие и характеристики нейропсихологической реабилитации.

Нейропсихологическая реабилитация является одним из видов реабилитации пациентов и связана с неврологическими и нейрохирургическими больными, имеющими специфическое заболевание, связанное с локальным повреждением головного мозга, следствием которого является нарушение высших психических функций.

Нейропсихологическая реабилитация - это комплекс мероприятий, направленных на реабилитацию определенной группы пациентов (с локальными поражениями мозга различной этиологии: инсульт, черепно-мозговая травма, опухоли головного мозга и др.). Нейропсихологическая реабилитация имеет свои задачи - реабилитация поврежденных психических функций.

Нейропсихологическая реабилитация имеет свои собственные методы реабилитации, которые состоят из ряда групп. Группа методов направлена на реабилитацию поврежденных высших психических функций, вторые включают в себя методы и мероприятия, реабилитирующие личный и социальный статус пациента путем обращения к его личности, окружающей среде, общения с окружающими и различных видов деятельности. При восстановлении высших психических функций специалист полагается на личность пациента, вовлекая его в процесс обучения.

Методы реабилитации взаимосвязаны, но на каждом этапе реабилитации та или иная группа методов становится доминантной, а не изолированной. То же самое относится и к целям и задачам нейропсихологической реабилитации. Основным и наиболее эффективным методом выздоровления является восстановление нарушенных психических функций, таких как речь, восприятие, чтение, письмо и т. д. Мы не достигнем большого прогресса, пока не поставим конкретный вопрос о путях восстановления пострадавшего.

Естественно, что задачи восстановления этого контингента больных могут быть полностью решены только через восстановление нарушенных психических функций и вследствие этого. Независимо от того, насколько сильно мы влияем на личность пациента или помещаем его в правильную социальную среду, мы не можем научить его говорить, писать, считать, читать. И пока пациент не может освоить навыки речевых функций, памяти, внимания, интеллектуальной активности и т. д., реабилитационный процесс не сможет нормально протекать и решать свои проблемы.
С другой стороны, восстановительное образование, как и весь реабилитационный процесс, должно апеллировать к личности пациента, но с помощью определенных методов, которые должны влиять на сам дефект и личность пациента, его эмоциональную и волевую сферы. В этом и заключаются особенности взаимодействия системы нейропсихологической реабилитации и одного из ее методов реабилитационной подготовки неврологических нейрохирургических больных.

Конечная цель реабилитации этих пациентов вернуть их в нормальное состояние, но не в упрощенную социальную среду. Эта цель может быть достигнута только путем решения основных недостатков. Реабилитация пациентов - понятие более широкое, чем нейропсихологическая реабилитация, но оба они направлены на достижение одной и той же цели. Нейропсихологическая реабилитация, в свою очередь, является более широкой концепцией, чем восстановление высших психических функций. Оба они направлены на одну цель, но при взаимодействии решают разные задачи. Задачами восстановления высших психических функций и восстановительной подготовки являются восстановление нарушенных функций, восстановление деятельности человека. Эффективное решение этих задач будет зависеть от эффективности нейропсихологической реабилитации, в задачи которой входит восстановление личного и социального статуса пациента, его положения в социальном обществе, в его различных малых социальных группах (семья, профессия и др.), восстановление всей системы отношений пациента.

Нейропсихологическая реабилитация и восстановление высших психических функций не взаимоисключают, а наоборот дополняют друг друга и взаимодействуют. Они связаны как структурно, так и функционально - ставя перед собой задачи и решая их, они стремятся к общей цели - возвращению больных к обществу и социальной жизни. Таким образом, мы будем понимать нейропсихологическую реабилитацию пациентов как системное воздействие на дефект с помощью специальных техник, в которых предусматривается также апелляция к личности и малой социальной терапевтической группе пациентов, направленное прежде всего на реабилитацию высших психических функций (а не приспособление к дефекту), как основная задача, решение которой приведет к достижению конечной цели - реабилитации больного, т. е. восстановление его личного и социального статуса, возвращение к обычной (не упрощенной) социальной среде, к общественной и трудовой деятельности. В проблеме реабилитации больных, в том числе и в нейропсихологической реабилитации проблема биологическая и социальная наиболее выделяется. Психологические принципы реабилитации пациента:

1. Принцип учета личности пациента. Восстановительная подготовка должна исходить из задач лечения человека, восстановления функций 
пациента, а не из задач изолированного восстановления каких-либо навыков. Чтобы успешно реабилитировать функцию, сначала нужно «восстановить активность и отправить ее». Известно, что характер деятельности субъекта определяется, прежде всего, мотивами, лежащими в его основе, т. е. причиной, по которой человек осуществляет эту деятельность. Мотивы могут быть разные, эффективность деятельности разная, потому что зависит от мотива. Поэтому в реабилитационной подготовке необходимо формировать мотивы пациентов.

2. Принцип опоры на сохраненные формы вербальной и невербальной деятельности больного, У больного в прошлом был большой социальный опыт, в частности, опыт интеллектуальной, речевой, трудовой, игровой деятельности. Этот опыт не исчезает, многие формы человеческой деятельности остаются неизменными. Чаще всего действия, подкрепленные в прошлом, которые происходят на менее произвольном уровне, сохраняются. Поэтому использование остаточных способностей наиболее продвинутых форм деятельности должно быть одним из важных принципов обучения. Опора на сохраненные формы деятельности (игровая деятельность, пение, чтение стихов, счет и т. д.) В процессе обучения позволяет временно передать затронутую функцию другому, более низкому и более доступному пациенту, уровню ее реализации.

3. Принцип опоры на предметную деятельность. Известно, что в деятельности субъекта формируются психические процессы. Вербальное общение - это тоже форма действия. В реабилитационной подготовке необходимо создавать методы восстановления речи через деятельность пациента, как вербальную, так и невербальную. Ассимиляция происходит через собственную деятельность субъекта, но эта деятельность должна быть организована.

4. Принцип организации деятельности больного. В современной психологии уже давно показано, что в преподавании важно не только содержание обучения и собственной учебной деятельности, но прежде всего организация и управление этой деятельностью.

5. Принцип программированного обучения. Принцип программирования (или систематического мониторинга извне) восстановления нарушенной функции является одним из способов реализации четвертого принципа. Пациент с афазией нуждается в такой организации своей деятельности и таких методах, которые позволили бы ему самостоятельно выполнять первые операции, а затем действия для выполнения задач (говорение, понимание, письмо и т. д.). Этот принцип предусматривает разработку программ, состоящих из серии последовательных операций, выполнение которых пациентом (сначала с помощью учителя, а затем независимо) приводит к реализации нарушенной способности говорить, понимать, писать и т. д. Расчленение действия, которое выполнялось автоматически и сокращенным способом до болезни (например, оптическое восприятие буквы, распознавание речевых звуков из уха, активная речь), на ряд последовательных операций, доступных пациенту, делая их внешними, сначала контроль, а затем самоконтроль за их выполнением - все это создает возможность для пациента выполнить нарушенное действие в самом начале тренировки.

К программам, созданным в рамках реабилитационного обучения, необходимо выдвигать ряд требований: избирательность в содержании программы, последовательность в выполнении операций, многократное повторение ( выполнение ) программы пациентами в процессе обучения, опора на внешние вспомогательные средства. Все это создает условия для высокой степени активности и самостоятельности пациента в преодолении дефектов.

Поначалу хорошо продуманная программа будет средством управления восстановлением функции, а после овладения ею, она будет действовать для пациента как средство самоуправления, как способ выполнения тех или иных действий.

Таким образом, можно сделать вывод: нейропсихологическая реабилитация больных эпилепсией, являясь самостоятельной частью общей реабилитации больных, страдающих различными заболеваниями, реализует общие цели - восстановление личного и социального статуса пациента, возвращение его в нормальную социальную среду, а не в упрощенную. Нейропсихологическая реабилитация имеет свои задачи, и прежде всего восстановление высших психических функций, а не адаптация пациента к дефекту. Только решение задачи по восстановлению речи и письма, чтения и счета, и т. д., может составлять основу нейропсихологической реабилитации пациентов. Восстановление высших психических функций является основной составляющей и задачей нейропсихологической реабилитации. Основной метод - это восстановительное обучение.

В качестве научной основы нейропсихологической реабилитации больных и восстановления высших психических функций представлены современные представления: а) о социально-историческом происхождении высших психических функций; б) об их прижизненном формировании; в) о комплексном взаимодействии биологического и социального, в результате которого в течение жизни человека формируются новые функциональные системы.

Концептуальный аппарат нейропсихологии также является научно-теоретической основой для восстановления высших психических функций: а) новые идеи о генезисе, образовании и распаде высших психических функций;

б) учение о функциональных системах как психофизиологической основе высших психических функций; в) изучение динамической и системной локализации высших мозговых функций в головном мозге; г) изучение «фактора», лежащего в основе функционального дефекта, на основании которого формируется синдром; е) новое исследование синдрома и симптома. 


\section{Список литературы:}

1.Максутова Э.Л., Железнова Е.В., Рогачева Т.А., Соколова Л.В., Токарева Н.Г. Принципы и формы реабилитации больных эпилепсией с психическими нарушениями: Пособие для врачей. M., 1997. - с.

2.Токарева Н.Г., Железнова Е.В. Клиническая оценка спеллинга у больных эпилепсией // Здоровье и образование в XXI веке. - 2016. - Т.18, №1. - С. 3133.

3.Токарева Н.Г., Железнова Е.В. Особенности медико-социальной реабилитации больных эпилепсией // Эл. научно-образовательный вестник Здоровье и образование в XXI веке. - 2015. - Т.17, №5. - С. 27-29.

4. Токарева Н.Г., Железнова Е.В. Клиникопсихологическая оценка внимания больных эпилепсией // Вестник Здоровье и образование в XXI веке. - 2016. - Т.18, №1. - С. 28-30.

5.Токарева Н.Г. Личность и болезнь: Я и виртуалистика: от инакомыслия до парадигматических революций. Материалы круглого стола. Саранск, 2009. - С. 133-134.

6.Aydemir N, Ezkara C, Жnsal P, Canbeyli R. A comparative study of health related quality of life, psychological well-being, impact of illness and stigma in epilepsy and migraine. Seizure. 2011, vol.20, pp. 679-85.

7.Chung YT, Hsieh IC, Lai MC, Huang CW The Potential Role of Neurocognitive Rehabilitation in Epilepsy. Int J Neurorehabilitation 2014, vol.1, pp.12531.

8.Elafros MA, Sakubita-Simasiku C, Atadzhanov $\mathrm{M}$, et al. Stigma and psychiatric morbidity among mothers of children with epilepsy in Zambia. Int Health. 2013, vol. 5, pp.288-94.

9.Friedrich L, Taslak M, Tomasovic S, Bielen I. How does the label 《epileptic》 influence attitudes toward epilepsy? Seizure. 2015, vol.33, pp.54-9.

10.Leaffer EB, Hesdorffer DC, Begley C. Psychosocial sociodemographic associates of felt stigma in epilepsy. Epilepsy Behav. 2014, vol.37, pp. 104-9.

\title{
SATISFACTION WITH JOB ASSIGNMENTS AND REWARD FOR HEALTHCARE PROFESSIONALS
}

\author{
Mihaela Mireva Ph D \\ Medical College "Jordanka Filaretova", \\ Medical university-Sofia
}

\section{УДОВЛЕТВОРЕННОСТЬ ОТ ДОЛЖНОСТНЫХ ЗАДАЧ И ВОЗНАГРАЖДЕНИЯ МЕДИЦИНСКИХ РАБОТНИКОВ}

\author{
Михаела Мирева д.м. \\ Медицински колеж “Йорданка Филаретова”, \\ Медииински университет-София
}

\begin{abstract}
In the sphere of healthcare in Bulgaria there have been frequent changes in the past 10 years, which affect not only the medical staff, but also the healthcare professionals - nurses, midwives, laboratory workers. Doctor-nurse imbalance became long lasting, due to the deficiency of nurses in many hospitals (especially in state-owned hospitals and in smaller towns). This paper focuses on the results of a survey of 65 health care professionals on job satisfaction and earnings. It has been made a quality and quantity analysis, the conclusions of which will be used for the practice.

\section{АННОТАЦИЯ}

В сфере здравоохранения в Болгарии за последние 10 лет произошли частые изменения, которые затрагивают не только персонал врачей, но и медицинских работников - медсестер, акушерок, лабораторных работников. Устанавливается постоянный дисбаланс по отношению врач-медсестра из-за нехватки медсестер во многих больницах (особенно в государственных и в небольших населенных пунктах). Эта статья посвящена результатам опроса 65 медицинских работников об удовлетворенности работой и полученных вознаграждений. Сделан качественный и количественный анализ, выводы, которых будут использованы для практики.

Key words: health, health care professionals, satisfaction, motivation, remuneration.

Ключевые слова: здороохранение, специалисты в области здравоохранения, удовлетворенность, мотивация, вознаграждение

\section{1. ВВЕДЕНИЕ:}

Активность, присущая каждому живому существу, у человека приобретает своеобразное проявление и специфичность, выраженные в деятельность. Основная характеристика деятельности является ее предметность. Результатом деятельности является определенный

продукт. В большинстве случаев то, что человек делает в своей профессиональной деятельности, предназначено для окружающих, для общества в целом и, в меньшей степени, для самого себя, принимается, что деятельность носит общественный характер. Индивидуальная деятельность воспринимается как часть
\end{abstract}

